\title{
A Case Report Discussing The Options for Placement of Glaucoma Drainage Devices in the Presence of Corneal Decompensation
}

\author{
Marlon J. Demeritt \\ Nova Southeastern University, dmarlon@nova.edu \\ Beata Lewandowska \\ Nova Southeastern University, blewandows@nova.edu
}

Follow this and additional works at: https://nsuworks.nova.edu/ijahsp

Part of the Medicine and Health Sciences Commons

\section{Recommended Citation \\ Demeritt MJ, Lewandowska B. A Case Report Discussing The Options for Placement of Glaucoma Drainage Devices in the Presence of Corneal Decompensation. The Internet Journal of Allied Health Sciences and Practice. 2017 Jan 01;15(2), Article 6.}

This Case Study is brought to you for free and open access by the College of Health Care Sciences at NSUWorks. It has been accepted for inclusion in Internet Journal of Allied Health Sciences and Practice by an authorized editor of NSUWorks. For more information, please contact nsuworks@nova.edu. 


\title{
A Case Report Discussing The Options for Placement of Glaucoma Drainage Devices in the Presence of Corneal Decompensation
}

\begin{abstract}
Purpose: The purpose of this case report is to discuss how the various placements of glaucoma drainage implants relate to corneal decompensation. Method: A 58-year Hispanic female presented for evaluation of decreased vision in the left eye for 2 years. This is a case report of a patient who underwent a secondary surgery to replace the anterior tube shunt implantation with a posterior shunt implantation following development of severe corneal decompensation. Results: Glaucoma tube shunt implants inserted into the ciliary sulcus of pseudophakic eyes shield the cornea offering protection against decompensation and avoid the risk of posterior segment complications.

Conclusions: Placement of glaucoma drainage implants into the ciliary sulcus in pseudophakic patients with shallow anterior chambers, abnormal irido-corneal anatomy, or those at risk for corneal decompensation is a safe and effective method of not only lowering the intraocular pressure but also protecting the cornea against decompensation. As primary eye care providers, optometrists need to know the various treatment options and adverse effects associated with each procedure.
\end{abstract}

\section{Author Bio(s)}

Marlon Demeritt, OD, MBA, FAAO is an Assistant Professor and Attending Optometrist at Nova Southeastern University College of Optometry and The Eye Care Institute.

Beata Lewandowska, $O D$ is an Assistant Professor and Attending Optometrist at Nova Southeastern University College of Optometry and The Eye Care Institute. 


\title{
IIJAHSP \\ The Internet Joưnal of Allied Health Sciences and Practice
}

Dedicated to allied health professional practice and education

Vol. 15 No. 2 ISSN 1540-580X

\section{A Case Report Discussing the Significance of Placement of Glaucoma Tube Shunt Implants}

\author{
Marlon J. Demeritt, OD, MBA, FAAO ${ }^{1}$ \\ Beata Lewandowska, OD ${ }^{2}$ \\ Nova Southeastern University \\ United States
}

\begin{abstract}
Purpose: The purpose of this case report is to discuss how the various placements of glaucoma drainage implants relate to corneal decompensation. Method: A 58-year Hispanic female presented for evaluation of decreased vision in the left eye for 2 years. This is a case report of a patient who underwent a secondary surgery to replace the anterior tube shunt implantation with a posterior shunt implantation following development of severe corneal decompensation. Results: Glaucoma tube shunt implants inserted into the ciliary sulcus of pseudophakic eyes shield the cornea offering protection against decompensation and avoid the risk of posterior segment complications. Conclusions: Placement of glaucoma drainage implants into the ciliary sulcus in pseudophakic patients with shallow anterior chambers, abnormal irido-corneal anatomy, or those at risk for corneal decompensation is a safe and effective method of not only lowering the intraocular pressure but also protecting the cornea against decompensation. As primary eye care providers, optometrists need to know the various treatment options and adverse effects associated with each procedure.
\end{abstract}

\section{Introduction}

Management of refractory glaucoma is challenging because classic treatment with ophthalmic medications or glaucoma filtering procedures is ineffective in controlling high intraocular pressure (IOP). Historically, implantation of glaucoma drainage devices (GDIs) have been used in order to obtain sufficiently low IOP in cases of refractory glaucoma. Glaucoma tube shunt implants can be placed in several sites within the eye: the irido-corneal angle, the posterior vitreous, or the ciliary sulcus. Because anterior chamber shunts avoid the need for vitrectomy, they are the primary surgical location when deciding to insert these implants, though $9.7 \%$ to $20.75 \%$ develop corneal edema following this procedure. ${ }^{1-4}$ Studies indicate that posterior tube implantation in the ciliary sulcus can be an effective treatment option for patients who develop corneal decompensation following anterior chamber shunt implantation. ${ }^{5}$ This is a case report of a patient who developed severe corneal decompensation after initial implantation of the glaucoma tube shunt in the irido-corneal angle. The patient subsequently underwent penetrating keratoplasty (PKP) and an additional surgery to have the tube re-positioned in the ciliary sulcus to prevent subsequent decompensation of the corneal transplant.

\section{Case Report}

A 58-year old Hispanic female presented for evaluation of decreased vision in the left eye over the past 2 years. Ocular history revealed glaucoma and pseudophakia in both eyes as well as a corneal transplant in the left eye.

Ocular surgical history was positive for phacoemulsification in both eyes in 2003 , trabeculectomy in both eyes in 2007, and iridocorneal angle tube implantation in the left eye in 2007. The patient reported the cornea in her left eye decompensated because of the implantation of the shunt into the irido-corneal angle in 2007. As a result of the corneal endothelial failure, the shunt was removed from the irido-corneal angle. In order to prevent decompensation of the donor cornea, insertion of the shunt in the ciliary sulcus was recommended and performed. In 2007, the patient underwent penetrating keratoplasty, vitrectomy and implantation of the shunt into the ciliary sulcus. 
At the time of the initial visit, the patient was using Pred Forte (prednisolone acetate) $1 \%$ ophthalmic suspension BID OS and Xalatan (latanoprost) $0.005 \%$ ophthalmic solution qhs OU. Best-corrected visual acuity was $20 / 25$ OD and 20/100 OS. Pupils were irregularly shaped in both eyes, with $2+$ reaction to light $\mathrm{OD}$ and no reaction to light OS. Biomicroscopy of the right eye revealed a superior clear, filtering bleb with negative Seidel's sign. Biomicroscopy of the left eye revealed a superior flat bleb, corneal graft with intact sutures, and areas of microcystic edema, posterior chamber intraocular lens, which appeared clear and centered with an open posterior capsule and an unobstructed tube positioned within the ciliary sulcus. See figures 1 and 2.

The intraocular pressure was measured by Goldmann applanation tonometry and recorded as $13 \mathrm{mmHg}$ OD and $07 \mathrm{mmHg}$ OS at 3:16 pm. Dilated fundus examination of the right eye showed a clear vitreous. The optic nerves were pink and distinct in both eyes and had a $0.35 / 0.35$ and $0.4 / 0.4$ cup-to-disc ratio, right and left eye respectively. The maculae, vessels, and peripheral retina were all within normal limits in the right eye. The left eye had a fixed, miotic pupil and corneal edema, so our views of the posterior pole were limited, and the periphery could not be assessed.

The patient's diagnoses were open angle glaucoma in both eyes, status post trabeculectomy in both eyes that failed in the left eye, status post penetrating keratoplasty in the left eye for corneal decompensation secondary to anterior chamber tube shunt, and status post vitrectomy and tube shunt replacement in the ciliary sulcus in the left eye.

Figure 1: External photograph of the left eye revealing corneal graft with intact sutures and edema. Arrow is pointing to the tube shunt positioned in the ciliary sulcus.

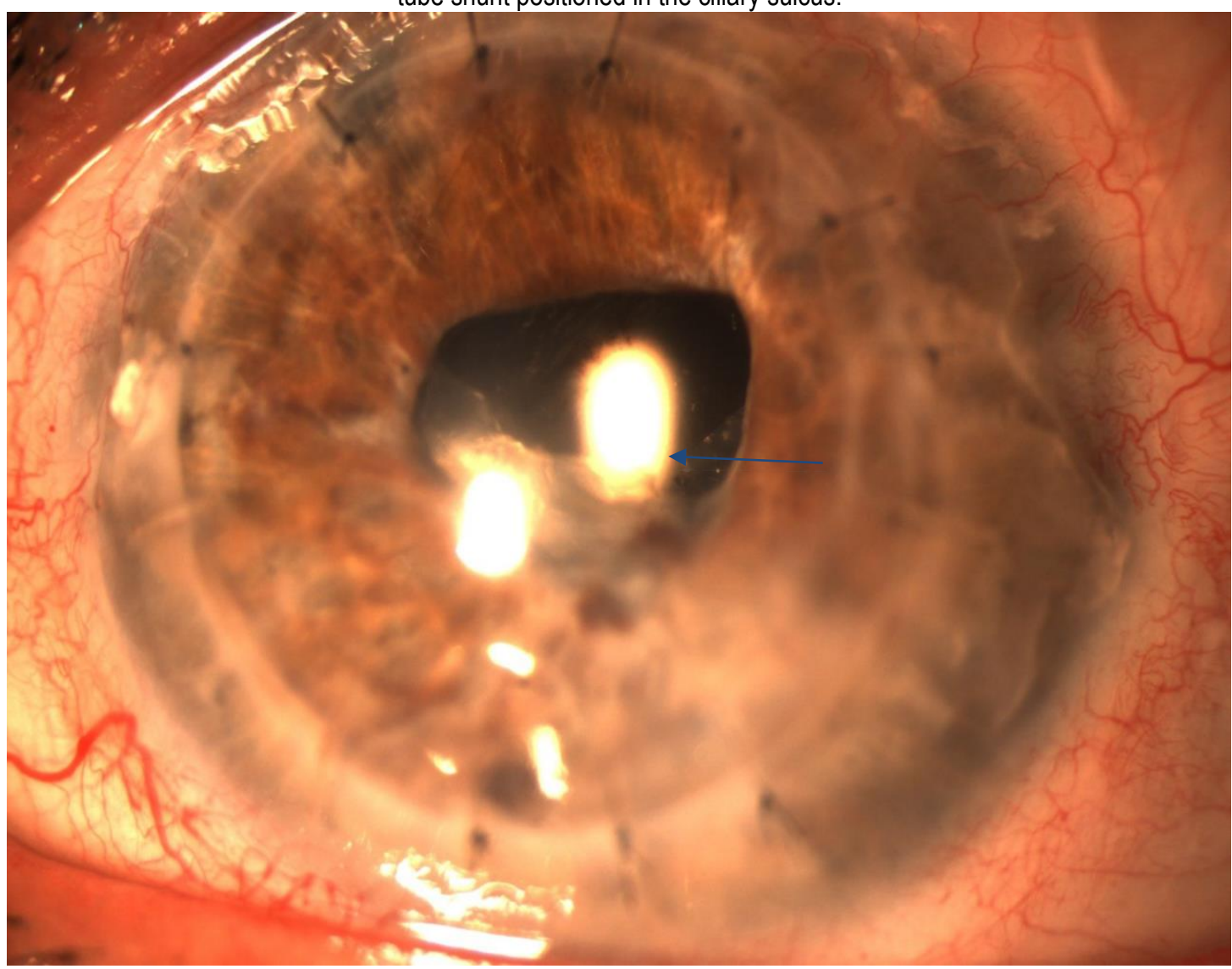


Figure 2: External photograph of the left eye with a magnified view of tube shunt positioned in the ciliary sulcus (see arrow).

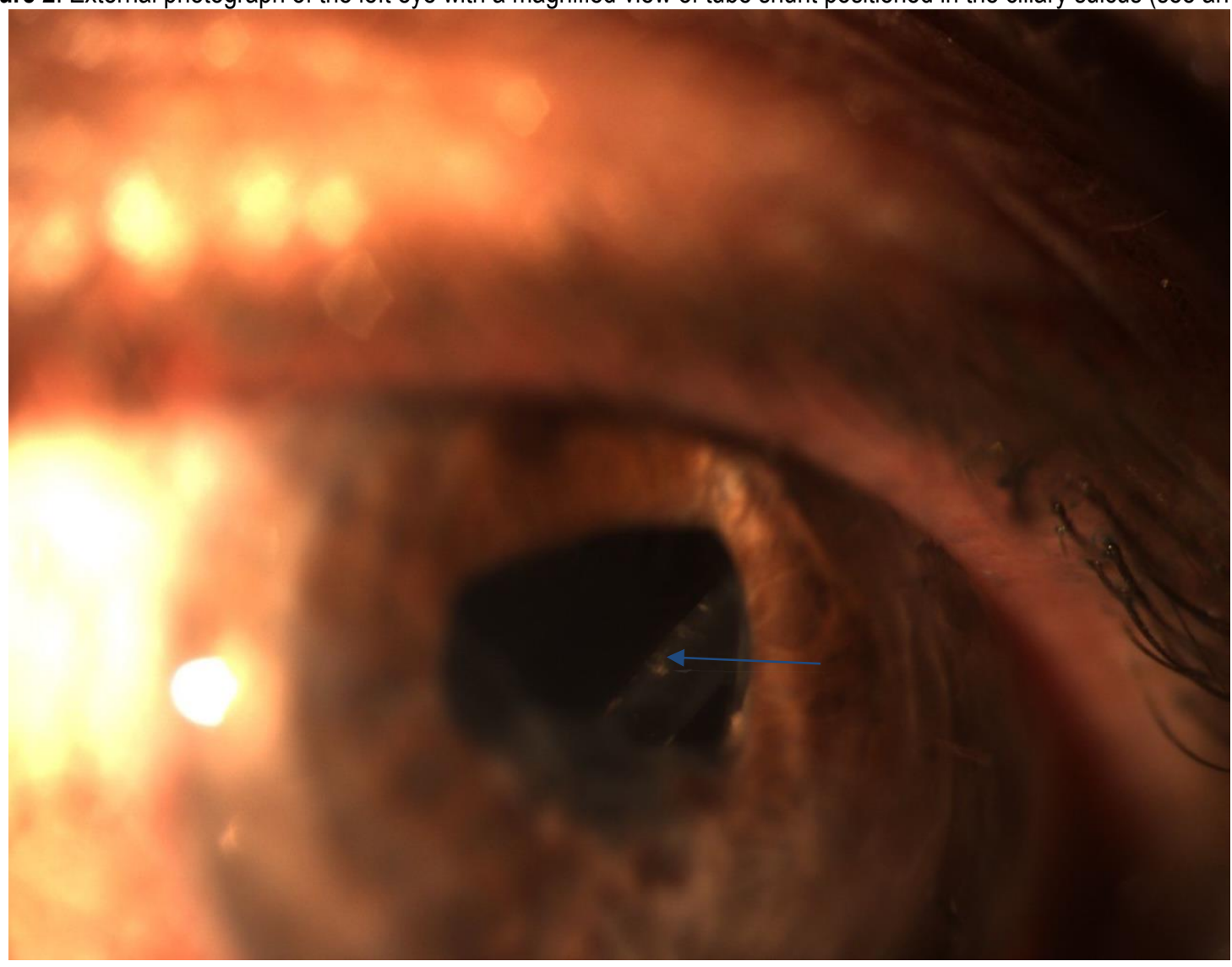

\section{Discussion}

Traditionally, the silicone tube of the glaucoma drainage device was placed in the anterior chamber. Introduction of the shunt into the anterior chamber is complicated by tube-corneal touch in $8 \%$ to $20 \%$ of patients and causes problems with corneal decompensation in $17 \%$ to $19 \%$ of patients. ${ }^{6,7}$ This is especially problematic in patients with pre-existing corneal disease (i.e. corneal edema, endothelial corneal dystrophy, Fuchs corneal dystrophy), corneal transplants, and shallow anterior chambers and abnormal irido-corneal angle anatomy. ${ }^{8}$ Placement of a shunt into the irido-corneal angle is preferred over the posterior chamber because it avoids the need for a vitrectomy. However, in patients with high risk for corneal decompensation, the pars plana approach, where the tube shunt is placed into the posterior chamber away from the cornea, has shown to be beneficial in controlling IOP and preserving vision. ${ }^{9}$

When the glaucoma drainage tube is placed into the pars plana, a pars plana vitrectomy is required. This procedure is performed to prevent vitreous from occluding the tube lumen. In cases of tube occlusion by vitreous remnants, $\mathrm{Nd}$ :YAG laser membranectomy may be performed to reopen the blocked tube shunt. Subsequent re-blockage within 2 months has been reported in $54 \%$ of cases. ${ }^{9}$ However, placement of the tube into the pars plana is also associated with corneal decompensation as well as posterior segment complications, such as epiretinal membranes and retinal detachments. It requires two procedures leading to increased surgical risks, increased costs, and complicated logistics of coordinating and scheduling both surgeries. ${ }^{10}$ Decreased risk of both corneal decompensation and posterior segment complications are considered significant advantages of implanting the glaucoma tube shunt in the ciliary sulcus. ${ }^{11}$

Eyes with shallow to moderate anterior chambers are at risk for developing corneal decompensation because of intermediate or continuous cornea-tube touch. ${ }^{11}$ When the tube is implanted into the irido-corneal angle of an eye with a shallow or moderate anterior chamber, the tube rests too closely to the corneal endothelium, and the cornea is subjected to decompensating. In cases where the tube may not be in continuous contact with the cornea, intermittent corneal endothelial damage may occur from anteriorly placed tubes during eye rubbing, sneezing, or even blinking. ${ }^{11}$ The ciliary sulcus is enclosed by the iris pigmented epithelium anteriorly, the ciliary processes posteriorly, and the anterior zonular fibers and lens capsule centrally. Implantation of 
the tube shunt in the ciliary sulcus of pseudophakic patients allows shielding of the cornea as the tube rests against the posterior surface of the intraocular lens. ${ }^{11}$

Most commonly reported postoperative complications associated with placing glaucoma drainage devices in the ciliary sulcus are small hyphemas and self-limiting serous choroidal detachments. ${ }^{11}$ Positioning the tube in the ciliary sulcus carries an increased risk of obstruction by the iris. However; should this occur, it can be remedied by in-office laser iridotomy. ${ }^{12}$ Ciliary sulcus tube shunts have not been associated with IOL dislocation, pigment dispersion, or significant loss of vision as a result of the procedure. ${ }^{9}$ Neither ciliary body separation nor suprachoroidal hemorrhage have been encountered in this procedure..$^{13}$ Insertion of the tube shunt in the ciliary sulcus is contraindicated in phakic eyes, as the integrity of the crystalline lens may become compromised. ${ }^{13}$ The procedure can also be performed in the presence of an anterior chamber intraocular lens. A major advantage of this procedure is the tube rests behind the intraocular implant ${ }^{13}$ Studies have shown that tube insertion in the ciliary sulcus in pseudophakic eyes is considered to be safe and effective at lowering intraocular pressure and lowers the risk of subsequent corneal decompensation. ${ }^{13-16}$

\section{Conclusion}

In summary, there are various methods for lowering intraocular pressure, including pharmacological, laser and surgical.17-19 In cases of refractory glaucoma, where conventional treatment with ophthalmic medications and trabeculectomy failed, glaucoma drainage device implantation is performed. As both anterior and posterior vitreous placement of the glaucoma drainage devices can result in post-surgical complications of corneal decompensation, alternative options have been employed. Tube shunt implant positioning in the ciliary sulcus serves as a safe and effective option for patients who developed corneal decompensation following anterior chamber tube shunt placement, those who are at risk for developing corneal decompensation, and those with high risk for complications during a pars plana vitrectomy. As primary eye care providers, optometrists need to understand the various treatment options and adverse effects associated with each procedure, specifically when it comes to placement of glaucoma drainage devices.

A part of this manuscript has been used in a poster presentation at The American Optometric Association 2016 meeting in Boston.

\section{References}

1. Topouzis F, Coleman AL, Choplin N, et al. Follow-up of the original cohort with the Ahmed glaucoma valve implant. Am J Ophthalmol. 1999;128(2):198-204. [PMID: 10458176]

2. Siegner SW, Netland PA, Urban RC Jr, et al. Clinical experience with the Baerveldt glaucoma drainage implant. Ophthalmology. 1995;102(9):1298-307. [PMID: 9097766]

3. Huang MC, Netland PA, Coleman AL, et al. Intermediate-term clinical experience with the Ahmed Glaucoma Valve Implant. Am J Ophthalmol. 1999;127(1):27-33. [PMID: 9932995]

4. Harbick KH, Sidoti PA, Budenz DL, et al. Outcomes of inferonasal Baerveldt glaucoma drainage implant surgery. $J$ Glaucoma. 2006;15(1):7-12. [PMID: 16378010]

5. Weiner $A$, Cohn $A D$, Balasubramaniam $M$, et al. Glaucoma tube shunt implantation through the ciliary sulcus in pseudophakic eyes with high risk of corneal decompensation. J Glaucoma. 2010;19(6):405-11. [PMID: 19907341]

6. Hill RA, Heuer DK, Baerveldt GM, et al. Molteno implantation for glaucoma in young patients. Ophthalmology. 1991;98(7):1042-6. [PMID: 1891211]

7. Lloyd MA, Sedlak T, Heuer DK, et al. Clinical experiences with single-plate Molteno implant in complicated glaucomas. Update of pilot study. Ophthalmology. 1992;99(5):679-87. [PMID: 1594211]

8. Joos KM, Laviña AM, Tawansy KA, et al. Posterior repositioning of glaucoma implants for anterior segment complications. Ophthalmology. 2001;108(2):279-84. [PMID: 11158799]

9. Prata TS, Mehta A, De Moraes CG, et al. Baerveldt glaucoma implant in the ciliary sulcus: midterm follow-up. J Glaucoma. 2010;19(1):15-8. [PMID: 19373099]

10. Varma R, Heuer DK, Lundy DG, et al. Pars plana Baerveldt tube insertion with vitrectomy in glaucomas associated with pseudophakia and aphakia. Am J Ophthalmol. 1995;119(4):401-7. [PMID: 7709964]

11. Weiner A, Cohn AD, Balasubramaniam M, et al. Glaucoma tube shunt implantation through the ciliary sulcus in pseudophakic eyes with high risk of corneal decompensation. J Glaucoma. 2010;19(6):405-11. [PMID: 19907341]

12. Polat J. More studies comparing placement sites of tube shunts needed. Ocular Surgery News U.S. Edition. Available at: http://www.healio.com/ophthalmology/glaucoma/news/print/ocular-surgery-news/\%7Bdb787e64-84da-4ba4-b9774624626cbbd6\%7D/more-studies-comparing-placement-sites-of-tube-shunts-needed. 2015. Accessed January 12, 2017. 
13. Rumelt S, Rehany U. Implantation of glaucoma drainage implant tube into the ciliary sulcus in patients with corneal transplants. Arch Ophthalmol. 1998;116(5):685-7. [PMID: 9596513]

14. Tello C, Espana EM, Mora R, et al . Baerveldt glaucoma implant insertion in the posterior chamber sulcus. $\mathrm{Br} J$ Ophthalmol. 2007;91(6):739-42. [PMID: 17301121]

15. Kolomeyer AM, Kim HJ, Khouri AS, et al. Pars plana Baerveldt tube insertion with pars plana vitrectomy for refractory glaucoma. Oman J Ophthalmol. 2012;5(1):19-27. [PMID: 22557872]

16. Prata TS, Mehta A, De Moraes CG, et al. Baerveldt glaucoma implant in the ciliary sulcus: midterm follow-up. J Glaucoma. 2010;19(1):15-8. \{PMID: 19373099\}

17. van der Valk R, Webers CA, Schouten JS, et al. Intraocular pressure-lowering effects of all commonly used glaucoma drugs: a meta-analysis of randomized clinical trials. Ophthalmology. 2005;112(7):1177-85. [PMID: 15921747]

18. Gracner T. Intraocular pressure response to selective laser trabeculoplasty in the treatment of primary open-angle glaucoma. Ophthalmologica. 2001;215(4): 267-70. [PMID: 11399933]

19. Schwartz KS, Lee RK, Gedde SJ. Glaucoma drainage implants: a critical comparison of types. Curr Opin Ophthalmol. 2006;17(2):181-9. [PMID: 16552254] 